\title{
MODELO VEC PARA LA ESTIMACIÓN DE INFLACIÓN BURSÁTIL: EVIDENCIA EMPIRICA EN MERCADOS NORTEAMERICANOS
}

Juan José Jordán Sánchez

\section{RESUMEN}

El presente trabajo estudia los efectos de cambios en la base monetaria y tasas de interés sobre los precios de las acciones en los mercados norteamericanos. La presente investigación considera cuatro series de tiempo: La primera variable a considerar se denomina como Índice Bursátil Ajustado, el cual se construyó a partir de datos de más de 5900 empresas pertenecientes a NYSE ${ }^{1}, \mathrm{NASDAQ}^{2}$ o $\mathrm{AMEX}^{3}$; para posteriormente identificar un proxy ${ }^{4}$ de inflación bursátil mediante la corrección de este índice por la cantidad de acciones disponibles del índice en cuestión en cada punto del tiempo analizado. Adicionalmente, se utilizaron los datos sobre capitalización de mercado para medir el crecimiento del valor de las empresas pertenecientes al índice, y datos sobre la emisión de base monetaria para establecer causalidad y las relaciones necesarias con el índice bursátil corregido. Finalmente, la última variable considerada es la tasa de interés real, la cual fue aproximada a través de los rendimientos de las Letras del Tesoro de USA con vencimiento a un año. Los resultados son congruentes con la hipótesis de Modigliani Cohn formulada en 1979, que sugiere que el mercado de valores extrapola incorrectamente los índices de crecimiento de precios pasado sin tomar en cuenta el impacto de la inflación en el tiempo [1]. Se logró verificar una correlación negativa entre incrementos de tasas de interés y el decremento de los precios de las acciones en diferentes rezagos temporales, lo que sugiere la existencia de inflación bursátil. Así mismo, se logró estimar un modelo VEC para la estimación del precio del índice bursátil a través de información histórica no contemporánea sobre la base monetaria y la capitalización de mercado.

Palabras Clave: Inflación Bursátil, Capitalización de Mercado, Índice, Base Monetaria, Tasas de Interés. 